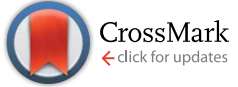

Cite this: RSC Adv., 2017, 7, 2578

\title{
Design and characterization of a microbial self- healing gel for enhanced oil recovery $\dagger$
}

\author{
Jun Wu, ${ }^{a}$ Hou-Feng Wang, ${ }^{a}$ Xian-Bin Wang, ${ }^{a}$ Hai-Yang Yang, ${ }^{b}$ Ru-Yi Jiang ${ }^{c}$ \\ and Raymond J. Zeng*a
}

Due to the heterogeneity of rock layers, the poor volumetric sweep efficiency of water and an invalid cycle have emerged as major problems in crude oil production. In this study, Sporosarcina pasteurii, the ureolytically active microorganisms, and the concentrated substrate were immobilized into the gels while the microorganisms could metabolize to produce ammonium, carbonate and EPS. The optimum immobilization formula was determined according to the microbial activity by detecting the ammonium concentration. Furthermore, the microscope images showed the uniform distribution of the microorganisms in the gels and the porosity of gels was propitious to the immobilization of the microorganisms. The reaction of precipitation happened immediately as soon as the carbonate anion was generated by the microorganisms in the gels and the EPS acted as not only an adhesive agent but also the nucleus of precipitation. As a consequence, the broken gels were healed again via the synergistic bridge effect among gel, calcium carbonate and EPS. In addition, the strength analysis revealed the excellent performance of self-healing gel and sand-packed columns experiment showed an improvement of oil recovery from $45.37 \%$ to $88.32 \%$. This microbial self-healing gel shows a promising application prospect to enhanced oil recovery.

Received 25th October 2016 Accepted 22nd December 2016

DOI: $10.1039 / c 6 r a 25814 j$

www.rsc.org/advances the reservoirs worldwide. ${ }^{4}$ After primary crude oil recovery, water is conventionally injected into the well to drive out secondary crude oil. In the highly permeable zones the secondary oil recovery is expected to be lower due to the loss of water and pressure. ${ }^{5}$ The volumetric sweep efficiency often dominates the recovery process when large variations between the viscosity of the recovery fluid and the oil or between the permeability of different zones of the formation exist. ${ }^{6}$ Therefore, tertiary or EOR methods including chemical and microbial ones have been proposed to solve this problem. ${ }^{7-9}$

Polymer flooding is a well-established technology with more than 40 years of application. ${ }^{9}$ Polymer can be used to increase the viscosity of the water phase while reducing the permeability of water to the porous rock, and thereby creating a more efficient and uniform front to displace oil from the reservoir. Due to the special network structure of the hyperbranched polymer, Lai et al. studied the permeability reduction performance of a hyperbranched polymer in the high permeability porous medium. ${ }^{10}$ Moreover, a water-soluble hyperbranched copolymer based on a dendritic structure for low-to-moderate permeability reservoirs has also been reported. ${ }^{11}$ However, the huge cost and shear force under the ground shall not be ignored if this hyperbranched polymer is really put into use. Microbial Enhanced Oil Recovery (MEOR) depends on microorganisms to degrade hydrocarbons and produce metabolites that are utilized in the oil recovery. ${ }^{12}$ Biosurfactant that is produced by indigenous microorganisms is used to enhance the fluidity and
${ }^{a}$ CAS Key Laboratory for Urban Pollutant Conversion, Department of Chemistry, University of Science \& Technology of China, Hefei 230026, PR China. E-mail: rzeng@ustc.edu.cn; Fax: +8655163600203; Tel: +8655163600203

${ }^{b}$ Department of Polymer Science and Engineering, University of Science \& Technology of China, Hefei 230026, PR China

${ }^{c}$ PetroChina Company Limited, Beijing 100007, PR China

$\dagger$ Electronic supplementary information (ESI) available. See DOI: $10.1039 /$ c6ra25814j 
reduce the capillary forces to promote the oil recovery. ${ }^{\mathbf{1 3 , 1 4}}$ Many researchers demonstrate that microorganisms and EPS can effectively reduce the permeability namely bioclogging via mathematic model and experiments, ${ }^{15-18}$ but incessancy nutrients have to be provided, leading to the high cost. Meanwhile, bioclogging is not secure due to the complex underground environment. As an effective tool, various biominerals have been proposed to reduce the permeability. Zhu et al. used anaerobic nitrate-dependent $\mathrm{Fe}(\mathrm{II})$ oxidation to form ferric hydroxide to plug the large flow channel for promoting oil recovery. ${ }^{19}$ Furthermore, microbially induced calcium carbonate precipitation (MICP) has been utilized to plug high permeability formation. For instance, Phillips et al. used MICP to reduce potential $\mathrm{CO}_{2}$ leakage by seal fracture ${ }^{20}$ and the field studies were performed to reduce the fractured rock permeability by using MICP. ${ }^{21,22}$

In recent years, there has been an increasing research in selfhealing hydrogels that can sense the change in their environment and accordingly adapt their function. ${ }^{23-26}$ Given the difference of multi-functional properties and environment, hydrogels have been tailored to respond to $\mathrm{pH}$, light, redox, etc. These high-performance hydrogels are expected to have diverse applications, such as drug-delivery systems, remotely actuated biosensors, shape memory materials and enhanced oil recovery. ${ }^{27-32}$ Injecting a polymer solution with a cross-linker, as a chemical method of EOR to form a polymer gel in subterranean formation during a few hours to several days for water shut, has been widely used in mature oil reservoir development. However, there are some disadvantages of these self-healing hydrogels, such as low temperature resistance, poor salt tolerance, and easy oxidative degradation.

In this study, the aim was to design a microbial self-healing gel to bioplug high permeability layers that led to the more uniform water movement through the reservoir for enhanced oil recovery. The microorganisms that can generate calcium carbonates biomineral and concentrated substrate/nutrients were immobilized in the gel. The optimum immobilization formula was evaluated. Furthermore, the structure of gels and distribution of the microorganisms were characterized with microscope. We hope that the broken gels could be healed by the bridge effect of calcium carbonate biomineral and EPS. If so, the microbial self-healing gels might have a good application prospect in enhanced oil recovery.

\section{Experimental}

\section{Chemicals}

All chemicals are commercially available and analytical grade used as received without further purification. Acrylamide (AM), sodium alginate (SA), ammonium persulfate (APS), $N, N^{\prime}$-methylenebisacrylamide (BIS), $\quad N, N, N^{\prime}, N^{\prime}$-tetramethylethylenediamine (TEMED), calcium chloride $\left(\mathrm{CaCl}_{2}\right)$, ammonium chloride $\left(\mathrm{NH}_{4} \mathrm{Cl}\right)$, sodium chloride $(\mathrm{NaCl})$, urea, peptone from casein and peptone from soymeal were purchased from Sinopharm Chemical Reagent Co., Ltd (Shanghai, China). Deionized water was used in all experiments.

\section{Microorganisms and cultivation}

Sporosarcina pasteurii (ATCC 11859), the ureolytically active microorganisms, were purchased from DSMZ (DSM No. 33) in Germany. The microorganisms were activated overnight to stationary phase firstly at $30{ }^{\circ} \mathrm{C}$ with the DSMZ medium 220 that consisted of $15.0 \mathrm{~g} \mathrm{~L}^{-1}$ peptone from casein, $5.0 \mathrm{~g} \mathrm{~L}^{-1}$ peptone from soymeal, $5.0 \mathrm{~g} \mathrm{~L}^{-1} \mathrm{NaCl}$ and $20.0 \mathrm{~g} \mathrm{~L}^{-1}$ urea then adjusted $\mathrm{pH}$ to 7.3. The microorganisms were washed via centrifugation (7000 rpm, $15 \mathrm{~min}$ ) and resuspended in fresh sterile concentrated medium composed of $30 \mathrm{~g} \mathrm{~L}^{-1}$ Difco Nutrient Broth, $200 \mathrm{~g} \mathrm{~L}^{-1}$ urea and $100 \mathrm{~g} \mathrm{~L}^{-1} \mathrm{NH}_{4} \mathrm{Cl}$ to an $\mathrm{OD}_{600}$ of 2 prior to the immobilization experiment.

\section{Preparation of the microbial immobilization system}

In order to obtain the optimum immobilization formula, 8 sets containing different formula were set up (Table 1). According to the experimental results (detailed description is shown in Results), the optimum immobilization formula was chosen to immobilize the microorganisms as below.

The solution (solution A) containing $2.5 \mathrm{~g} \mathrm{~L}^{-1}$ APS and $30 \mathrm{~g}$ $\mathrm{L}^{-1} \mathrm{CaCl}_{2}$ were prepared firstly then put it into $4{ }^{\circ} \mathrm{C}$ refrigerator for $30 \mathrm{~min}$. APS was the initiator of $\mathrm{AM}$ and $\mathrm{CaCl}_{2}$ was the crosslinker of SA. $0.4 \mathrm{~g}$ SA, $1 \mathrm{~g}$ AM, $0.04 \mathrm{~g}$ BIS and $0.12 \mathrm{~mL}$ TEMED were added to the $20 \mathrm{~mL}$ microorganisms suspension and stirred with magnetic stirrer until dissolving completely (solution B). $10 \mathrm{~mL}$ syringe was used to absorb solution B and added into the solution A (Fig. S1 $\dagger$ ). When the drops contacted the solution, pellets were formed immediately. The pellets were taken out after crosslinking for $2 \mathrm{~h}$ and rinsed 3 times with phosphate buffer (pH 7.0). In order to simulate the shearing force for gels, we utilized 20 mesh steel screen to cut the pellets into smaller particles. Ultimately, the broken gels were added into $200 \mathrm{~mL}$ simulated underground water mainly composed of $0.1 \mathrm{M} \mathrm{CaCl}_{2}$.

\section{Determination of microorganisms activity}

The reaction steps and overall reaction are as follows:

$$
\begin{gathered}
\mathrm{CO}\left(\mathrm{NH}_{2}\right)_{2}+\mathrm{H}_{2} \mathrm{O} \rightarrow 2 \mathrm{NH}_{3}+\mathrm{CO}_{2} \\
\mathrm{NH}_{3}+\mathrm{H}_{2} \mathrm{O} \rightarrow \mathrm{NH}_{4}^{+}+\mathrm{OH}^{-} \\
\mathrm{CO}_{2}+\mathrm{OH}^{-} \rightarrow \mathrm{HCO}_{3}^{-}
\end{gathered}
$$

\section{Table 1 Different immobilization formula ${ }^{a}$}

\begin{tabular}{lllllllll}
\hline Set & 1 & 2 & 3 & 4 & 5 & 6 & 7 & 8 \\
SA & 2.0 & 2.0 & 2.0 & 2.0 & 3.0 & 3.0 & 3.0 & 3.0 \\
AM & 5.0 & 10.0 & 15.0 & 20.0 & 5.0 & 10.0 & 15.0 & 20.0 \\
BIS & 0.2 & 0.3 & 0.5 & 0.7 & 0.2 & 0.3 & 0.5 & 0.7 \\
TEMED & 0.6 & 1.3 & 2.0 & 2.5 & 0.6 & 1.3 & 2.0 & 2.5 \\
APS & 0.25 & 0.5 & 0.75 & 1.0 & 0.25 & 0.5 & 0.75 & 1.0 \\
$\mathrm{CaCl}_{2}$ & 3.0 & 3.0 & 3.0 & 3.0 & 5.0 & 5.0 & 5.0 & 5.0
\end{tabular}

${ }^{a}$ All the units are based on $(\%, w / v)$. 


$$
\mathrm{HCO}_{3}{ }^{-}+\mathrm{Ca}^{2+}+\mathrm{OH}^{-} \rightarrow \mathrm{CaCO}_{3}+\mathrm{H}_{2} \mathrm{O}
$$

Overall reaction:

$$
\mathrm{CO}\left(\mathrm{NH}_{2}\right)_{2}+2 \mathrm{H}_{2} \mathrm{O}+\mathrm{Ca}^{2+} \rightarrow \mathrm{CaCO}_{3}+\mathrm{H}_{2} \mathrm{O}+2 \mathrm{NH}_{4}^{+}
$$

Therefore, the concentration of ammonium could be used to determine the activity of microorganisms. Water Aquakem 200 quality autoanalyzer (ThermoFisher Scientific, Finland) was utilized to test the concentration of ammonium based on hypochloric acid and salicylic acid reagents spectrophotometry. ${ }^{33}$

\section{SEM and XRD analysis}

Scanning electron microscopy (SEM) and powder X-ray diffraction (XRD) were used to characterize the structure and morphology of the gel before and after microbial self-healing. The gel was dehydrated for $10 \mathrm{~min}$ successively in each of 50, 80 , and $98 \%$ ethanol. Scanning electron microscopy analysis was performed on a field emission SEM microscope (TESCAN MIRA 3) with the operation acceleration voltage of $5 \mathrm{kV}$. The samples for SEM analysis were coated with a thin film of platinum to increase the conductivity. Energy-dispersive X-ray spectroscopy (EDX) was applied for elemental composition analysis of the mineralized products. The powder X-ray diffraction patterns were recorded with a Philips X'Pert ProSuper X-ray diffractometer equipped with graphite monochromatized $\mathrm{Cu} \mathrm{K} \alpha$ irradiation $(\lambda=0.154056 \mathrm{~nm})$, employing a scanning rate of $0.02^{\circ} \cdot \mathrm{s}^{-1}$ in the $2 \theta$ range $10-70^{\circ}$.

\section{Distribution of the microorganisms and gel structure}

Distribution of microorganisms was conducted using a fluorescence microscope (Olympus BX51, Japan). Before the microscopy observation, the microorganisms immobilized in the gel was fixed with $4 \%(\mathrm{w} / \mathrm{v})$ paraformaldehyde at $4{ }^{\circ} \mathrm{C}$ for $2 \mathrm{~h}$ then washed with $1 \times$ phosphate-buffered saline (PBS). Microorganisms immobilization system were stained with $4^{\prime}$, 6-diamidino2-phenylindole (DAPI) and cut into slices with microtome (Leica CM1950, Germany).$^{33}$ Eventually, the slice was transferred onto the well of a microscope slide before observation. The phase contrast microscope (Olympus IX81, Japan) was used to analyze the gel structure from the slices.

\section{Measurement of temperature, strength, and salinity for microbial self-healing gel}

The temperature sweep test for microbially self-healing gel was carried out on an ARES-G2 rheometer (TA Instruments, USA) at a constant frequency of $5 \mathrm{rad} \mathrm{s}^{-1}$ and strain of $0.03 \%$ while the temperature varied from 0 to $80{ }^{\circ} \mathrm{C}$. The strength measurement under different shear strain was conducted using a cone-plate of $40 \mathrm{~mm}$ diameter with a cone angle of $1^{\circ}$. The storage modulus $\left(G^{\prime}\right)$ and loss modulus $\left(G^{\prime \prime}\right)$ were recorded as a function of shear strain and the temperature was kept at $25{ }^{\circ} \mathrm{C}$ using water bath.

The effects of temperature on the microbial immobilization system were conducted under $20,30,40$, and $50{ }^{\circ} \mathrm{C}$, respectively in a shaker incubator at $150 \mathrm{rpm}$. $\mathrm{NaCl}$ and $\mathrm{MgCl}_{2}$ were chosen as the examples to study the effect of salinity on the microbial immobilization system. The growth medium containing $10 \mathrm{~g}$ $\mathrm{L}^{-1} \mathrm{NaCl}, 10 \mathrm{~g} \mathrm{~L}^{-1} \mathrm{MgCl}_{2}$, and $5 \mathrm{~g} \mathrm{~L}^{-1} \mathrm{NaCl}$ and $\mathrm{MgCl}_{2}$ mixture respectively were prepared as described in ESI. $\dagger$ The microbial immobilization system was cultivated in a shaker incubator under the conditions of $30{ }^{\circ} \mathrm{C}, 150 \mathrm{rpm}$. Timing sampling was taken to measure the ammonium concentration, which was used to determine the activity of microorganisms.

\section{Sand-packed columns experiment}

The sand-packed columns experiment was conducted with a setup as shown in Fig. S2. $\dagger$ The column set containing a fine sand column and a coarse sand column was constructed with a $1.0 \mathrm{~L}$ column and a rubber plug. The sands were immersed in $1 \mathrm{M} \mathrm{HCl}$ for $12 \mathrm{~h}$ and then rinsed with deionized water until a neutral $\mathrm{pH}$ was reached, prior to scraping into the column. Gauze was placed on both ends of the glass column to prevent the sands from leaking out. The basic column parameters are displayed in Table S1 in the ESI. $\uparrow$ Three hundred milliliters of machine oil (Shell Helix Ultra 5W-40) was injected into fine sand and coarse sand column, respectively. The water flooding was used to flush the oil-saturated column at $2.5 \mathrm{~mL} \mathrm{~min}^{-1}$ by a peristaltic pump (BT100-1L, Longer Company, Baoding, China) to simulate the oil production process in situ until no oil was found in the effluent. Next, the microbial immobilization system was injected into the coarse sand column. The $\mathrm{CaCl}_{2}$ solution $(0.1 \mathrm{M})$ was continuously fed into the column at $2.5 \mathrm{~mL}$ $\min ^{-1}$. The volume of oil was measured daily by adding $\mathrm{NaCl}$ to promote the separation of the mixture of oil and water.

\section{Results and discussion}

\section{Optimum immobilization formula and the activity of microorganisms}

According to the concentration and rate of ammonium production, the optimum immobilization formula was determined because the more and faster ammonium were produced, the higher activity the microorganisms possessed. The prepared gels showed harder based on the hand feeling in Set 5-Set 8 than Set 1-Set 4 due to the different amount of sodium alginate. With the purpose of demonstrating the difference of hardness induced from different amount of sodium alginate, Set 1 and Set 5 containing nearly same formula except the difference of sodium alginate amount were selected to test the hardness with the rheometer. The result was consistent with our speculation that different amount of sodium alginate resulted in different hardness of gel, and more amount of sodium alginate possessed the harder structure (Fig. S3†). The rate of ammonium production was faster in Set 1 than other sets among Set 1 to set 8 before 2.5 days, and Set 5 took the second place while Set 4 and Set 8 were the slowest (Fig. 1). It was possibly attributed to the toxicity of acrylamide due to Set 4 and Set 8 containing more acrylamide than Set 1 and Set $5 .^{34}$ Furthermore, the harder gel brought about more difficult mass transfer so the ammonium production rate in Set 1 was higher than that in Set 5. It illustrated that the immobilization formula in Set 1 was the most 


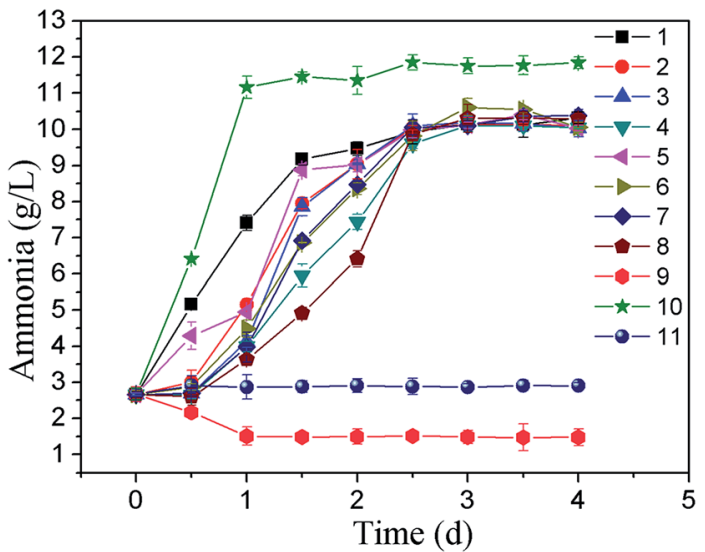

Fig. 1 Comparison of microbial activity of different immobilization formula and controls.

suitable for microbial survival, thus it was chosen as the optimum immobilization formula for the latter immobilization. The concentration of ammonium after 4 days achieved a balance at about $10 \mathrm{~g} \mathrm{~L}^{-1}$ in all immobilization sets (Fig. 1). No microorganism was immobilized in Set 9 to understand the relationship between the ammonium concentration and gel absorption. In order to estimate the effect of immobilization on activity of microorganisms, microbial suspension without using immobilization system was utilized in Set 10 . Set 11 that did not contain microbial immobilization system and microorganisms except the nutrient medium was as a blank control. The rate of ammonium production in microbial suspension was obviously the fastest (Fig. 1). The rate of ammonium production at the first day in Set 1 and Set 10 reached to $4.75 \mathrm{~g} \mathrm{~L}^{-1} \mathrm{~d}^{-1}$ and $8.50 \mathrm{~g}$ $\mathrm{L}^{-1} \mathrm{~d}^{-1}$, respectively, and it demonstrated that the activity of immobilization was $55.91 \%$ of microorganisms' suspension. In addition, the ammonium concentration in the immobilization set 1 was $10.2 \mathrm{~g} \mathrm{~L}^{-1}$, which was $1.5 \mathrm{~g} \mathrm{~L}^{-1}$ less compared to in Set 10. This was likely due to the absorption of gel. No change was found in Set 11 when no microorganisms or gel was added. There was a slight reduction by $1.3 \mathrm{~g} \mathrm{~L}^{-1}$ of the ammonium concentration in Set 9 resulted from the absorption of gel and this was almost consistent with aforementioned reduction in Set 10 (Fig. 1).

\section{Structure of gel and distribution of immobilized microorganisms}

Optical microscopy and scanning electron microscopy were used to characterize the structure of gel. Many dendritic-like pores were evenly bestrewed interior of gel and the pore diameter was approximate $100 \mu \mathrm{m}$ (Fig. 2A). The transaction of gel also showed the porous structure with SEM and the pore diameter was similar to the observation of optical microscopy (Fig. 2B). The porosity of gel provided an outstanding capacity to immobilize microorganisms and it was also significant for the mass transfer especially calcium, carbonate and ammonium that were essential to produce the precipitation. Dyed microorganisms were uniformly distributed in the gel according to

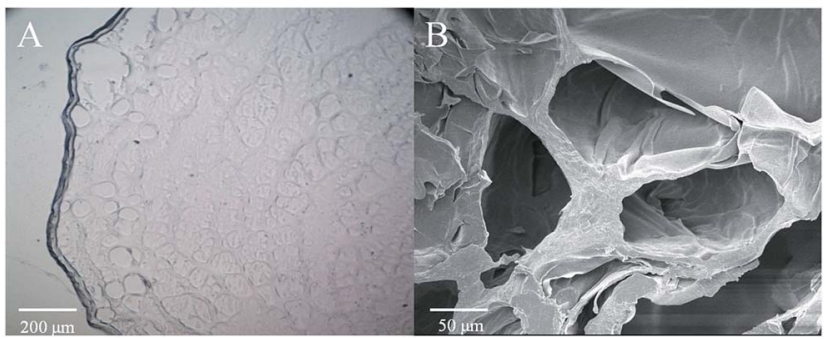

Fig. 2 Characterization of the gel structure with microscopy. (A) Optical microscopy (B) scanning electron microscopy.

the fluorescence microscope image, which demonstrated the remarkable immobilization of microorganisms inside the gel (Fig. 3). Our gel apparently possessed similar property with previous researches. For example, the calcium alginate gel that showed a spongy structure was used to immobilize the microalgae, and the microalgae were randomly distributed in the microcavities of gel..$^{35}$ Tian et al. found that the stable network matrices of PVA-boric acid gel could create a biocompatible environment to provide mechanical and chemical stability. ${ }^{36}$

\section{Development of calcium carbonate}

Calcium carbonate is vital for the microbial self-healing gel so the development of calcium carbonate was recorded with time during the experiment. No calcium carbonate was found at the first day but a small amount of calcium carbonate was produced in the gel at the second day. With the time went on, calcium carbonate extended from inner to outer of gel and the chunk got bigger and bigger. Calcium carbonate nearly filled the gel full after 6 days (Fig. 4). Apparently, calcium diffused into the interior of gel before $\mathrm{CO}_{3}{ }^{2-}$ was generated by microorganisms, then the reaction happened leading to the precipitation as soon as $\mathrm{CO}_{3}{ }^{2-}$ was produced. These explained the phenomenon well that calcium carbonate was developed from inside to outside. In addition to be as an adhesive, the formed calcium carbonate can also be used to plug high permeability in the media. Nemati et al. reported microbially formed calcium carbonate to modify the permeability profile and the permeability of unconsolidated porous media decreased due to plugging of calcium carbonate ${ }^{37}$ Phillips et al. performed a filed study that demonstrated microbially formed

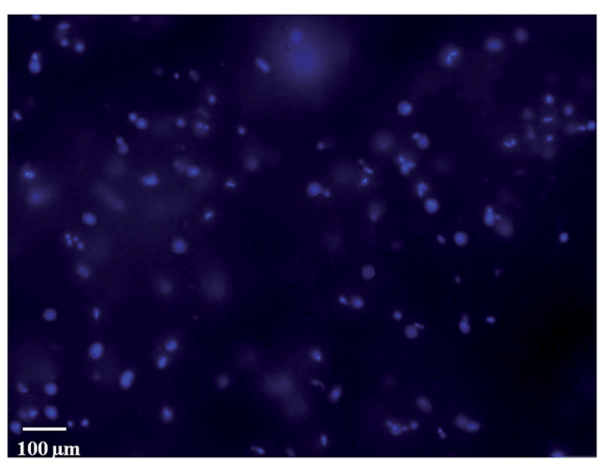

Fig. 3 Distribution of the microorganisms in the gel. 

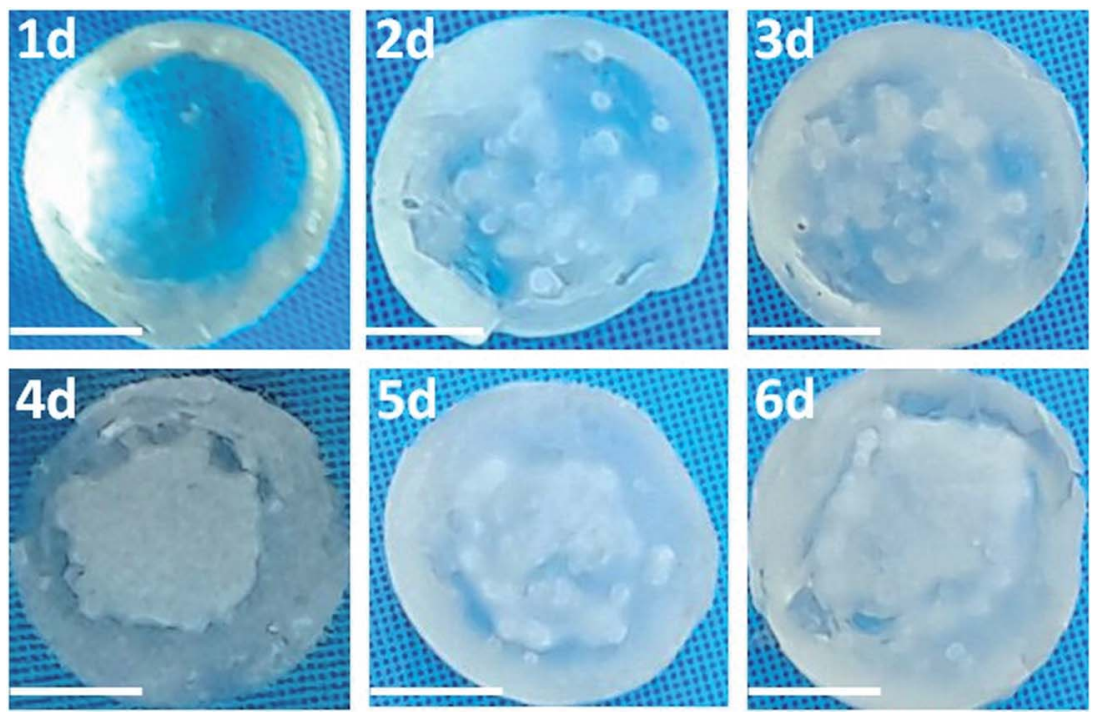

Fig. 4 Development of calcium carbonate with the time in the gel. Scale bar $=1 \mathrm{~mm}$.

calcium carbonate was a promising tool for sealing subsurface fractures in the near wellbore environment. ${ }^{22}$ Thus, the synergistic effect of self-healing gel and calcium carbonate can bring an exceedingly good performance to achieve plugging effectiveness.

\section{The profiles of the microbial self-healing gel}

The shear degradation of gels can be caused by high injection rates. ${ }^{38}$ In order to simulate the shear of hydraulic force when the gels were injected into the reservoir with pump, we broke the gel into smaller particles (Fig. 5A). After cultivating for a week, the gels began to form a big lump which could be clamped steadily with tweezers (Fig. 5B). A large number of powdery calcium carbonate wrapped around the gels and a few of mucus were also found near to the outside of the gel. It exhibited an excellent effectiveness of self-healing visually.

Furthermore, the microbial self-healing gels were observed with SEM after freeze drying. It turned out that spherical calcium carbonate crystal stacked tightly and cotton-shaped dried gels covered on the surface of calcium carbonate (Fig. 6). It indicated that calcium carbonate as a kind of biomineral produced by microorganisms functioned as a bridge between gels so as to achieve the effectiveness of microbial selfhealing. In addition, in order to understand the phase of

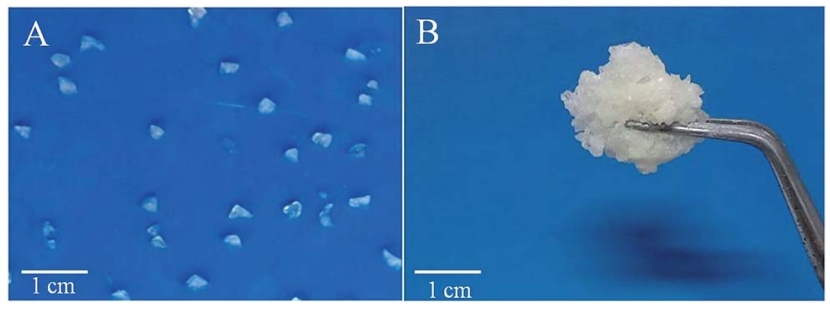

Fig. 5 Images of the gels (A) before (B) after microbial self-healing.

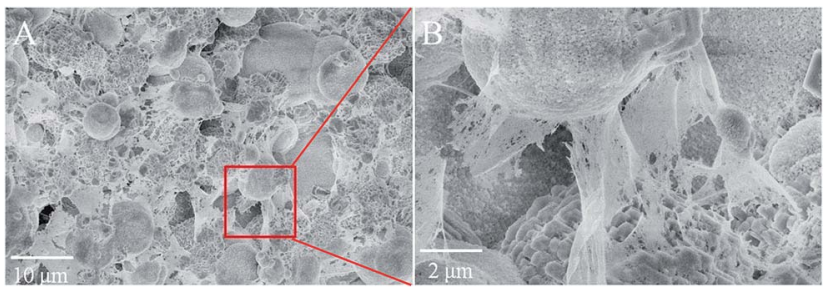

Fig. 6 Scanning electron microscopy of the microbial self-healing gel. (A) Microbial self-healing gel (B) enlargement of red rectangle.

calcium carbonate that usually existed as calcite, aragonite and vaterite, powder X-Ray Diffraction (XRD) was used to test the sample after SEM. The result revealed that the polymorph of calcium carbonate was a mixture of calcite and vaterite (Fig. S4 $\dagger$ ). According to the related research, the phase of calcium carbonate induced by microorganisms usually was calcite due to the thermodynamic stability. ${ }^{39,40}$ However, it was the mixture in our study, which might obtain some supports from Wang's study that sodium alginate as a type of polysaccharide could affect the structure and phase of calcium carbonate precipitate. ${ }^{41}$

\section{The effectiveness evaluation of microbial self-healing gel}

Complex formation characteristics are common in oil reservoirs, ${ }^{42}$ in order to meet the complex formation conditions underground, the effects of different temperature, shearing strain and salinity on the microbial self-healing gel and microbial immobilization system were evaluated. Firstly, the gels after self-healing were taken to test the strength under different temperature. As shown in Fig. 7A, the elastic modulus $\left(G^{\prime}\right)$ and viscous modulus $\left(G^{\prime \prime}\right)$ exhibited a little change when the temperature was less than $60{ }^{\circ} \mathrm{C}$, then decreased with the temperature continuous increase. Hao et al. designed thermalresponsive self-healing hydrogel based on hydrophobically 

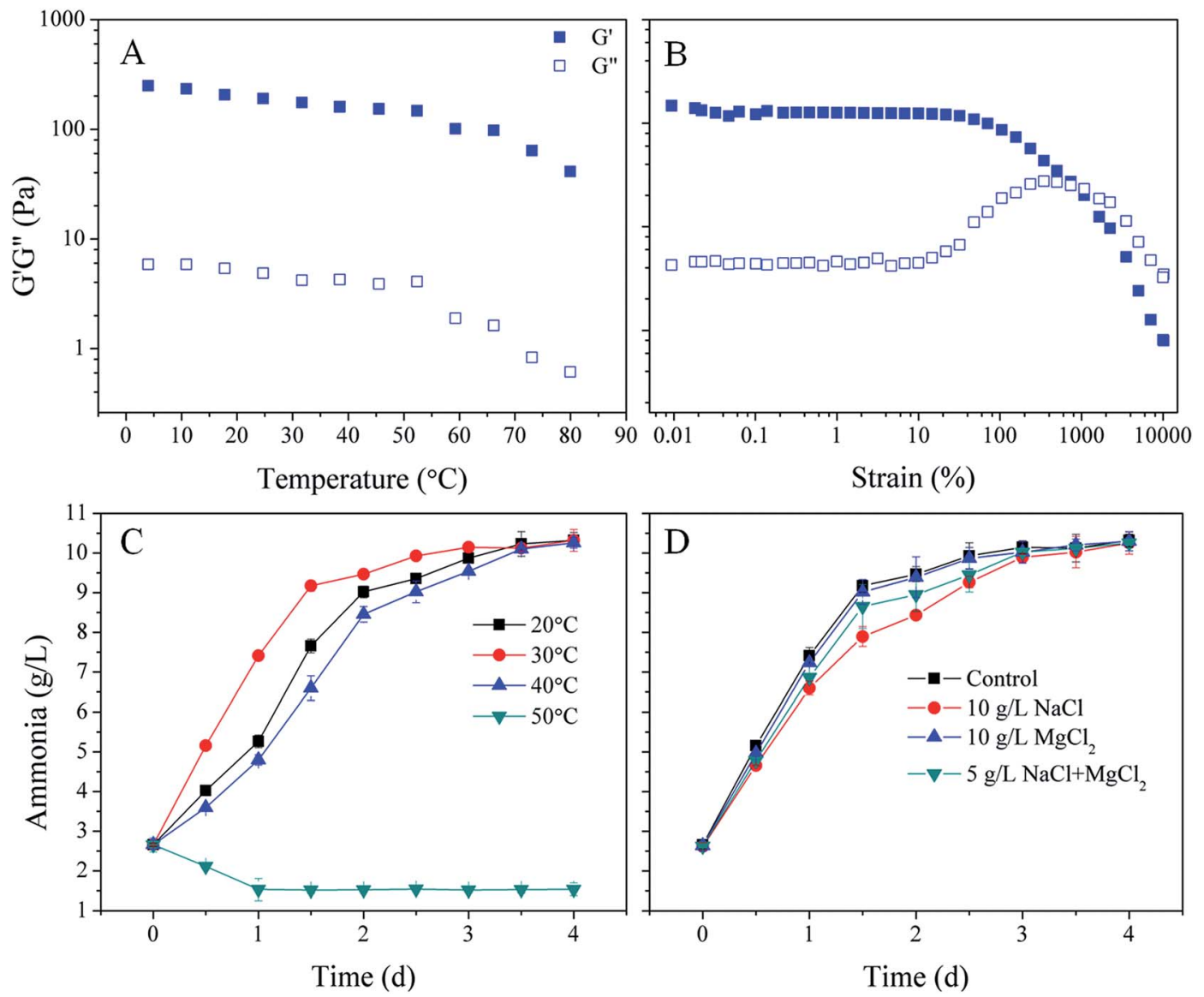

Fig. 7 Strength analysis of microbial self-healing gel under (A) different temperature and (B) different shearing rate; the effects of (C) temperature and (D) salinity on microbial immobilization system.

modified chitosan and vesicle. The sol-gel transition happened between $40-50{ }^{\circ} \mathrm{C}$ when $0.4 \% \mathrm{hm}$-chitosan with various concentration ratios of dodecyltrimethylammonium bromide and 5-methyl salicylic acid were used. ${ }^{43}$ As well known, the solgel transition occurs when $G^{\prime}$ is equal to $G^{\prime \prime}$, and the behavior is largely elastic with $G^{\prime}>G^{\prime \prime}$, revealing that the gels have typical viscoelastic properties. However, there was no sol-gel transition to be found in our study that indicated the stability was possessed by microbial self-healing gel from $0-80{ }^{\circ} \mathrm{C}$ (Fig. 7A). The strength analysis under different shear forces was carried out to estimate the shear resistance of microbial self-healing gel. Prior to reaching to the critical point, the gels displayed splendid performance and the strength kept the high value namely of high $G^{\prime}$ and $G^{\prime \prime}$. When the shear force increased to $900 \%$, the strength of gels declined drastically from 100 Pa to 10 Pa (Fig. 7B). Similar measurements were carried out for kappacarrageenan and kappa-carrageenan/epoxy-amine ICE hydrogels in previous studies, and the strength reduction appeared between $1-100 \%$ of shear strain. ${ }^{44}$ However, our self-healing gel could endure $900 \%$ shear strain that showed a better strength performance. Furthermore, four different temperatures, 20, 30, $40,50{ }^{\circ} \mathrm{C}$, were set to study the effect of temperature on microbial immobilization system and the concentration of ammonium was as the evaluative criteria. As depicted in Fig. 7C, microbial immobilization system in $30{ }^{\circ} \mathrm{C}$ showed the highest activity than $20{ }^{\circ} \mathrm{C}$ and $40{ }^{\circ} \mathrm{C}$, and a slight reduction of ammonium was found at $50^{\circ} \mathrm{C}$ after 1 day cultivation that may be ascribed to the absorption of gel based on prior experiment (Fig. 1). From the batch test, the microorganisms immobilized in gels could not bear the high temperature even at $50{ }^{\circ} \mathrm{C}$. However, MICP was driven by the urease secreted by microorganisms while the urease could have a good performance even at $80^{\circ} \mathrm{C} .{ }^{45}$ Therefore, enzymatic immobilization strategy may be an alternative way in high temperature oil reservoir. ${ }^{22}$ Compared with the control group (no salts addition), the salinity using different concentrations of $\mathrm{NaCl}$ and $\mathrm{MgCl}_{2}$ showed small influence on the reactivity of microorganisms. It demonstrated that salinity had small adverse effect on the microbial immobilization system. The protective effect of gels for microorganism and the occurrence of precipitation of $\mathrm{MgCO}_{3}$ may be responsible for it. ${ }^{46}$

An oil-saturated sand-packed columns experiment was performed to determine the effectiveness of microbial self-healing gel in EOR. Due to the difference of grain size between the fine and coarse sand columns (Table S1 $\uparrow$ ), the initial water flooding almost went through the coarse sand column that finally brought $272.2 \mathrm{~mL}$ oil out from the coarse sand column in three days, and the percentage of oil recovered was only $45.37 \%$ 


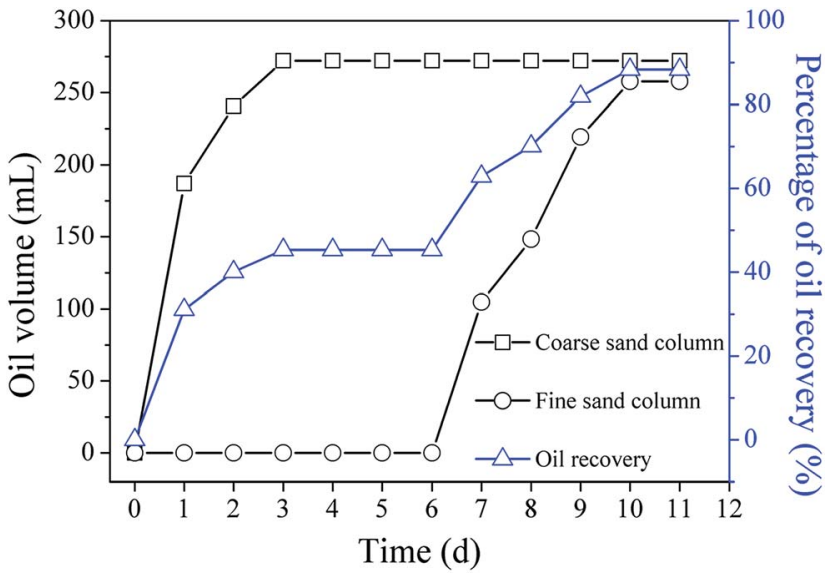

Fig. 8 Oil recovered from the sand-packed columns set.

(Fig. 8). Then, the microbial immobilization system was rejected into coarse sand column followed by an injection of $\mathrm{CaCl}_{2}$ solution. Interestingly, the $\mathrm{CaCl}_{2}$ solution had been diverted from the coarse sand column to the fine sand column four days latter, the volume of oil from the fine sand column began to increase on the 7th day until $257.70 \mathrm{~mL}$ oil was flushed out from the fine sand column. As a result, the final percentage of oil recovery rose from $45.37 \%$ to $88.32 \%$ (Fig. 8). Due to the EPS and calcium carbonate precipitation were induced by the microorganisms that resulted in the formation of microbial self-healing gel. Therefore, the coarse sand column was constantly plugged and the flow direction switched from the coarse sand to the fine sand, and finally switched completely to the fine sand column. Consequently, the oil in fine sand column was flushed out leading to high oil recovery. From the sandpacked columns experiment, the benefit of microbial selfhealing gel for enhancing oil recovery was successfully demonstrated via the laboratory displacement experiment.

\section{Mechanism of microbial self-healing gel}

In order to explain the mechanism of microbial self-healing gel, synergistic bridge effect among gels, EPS and biomineral has been proposed (Fig. 9). Microorganisms and nutrients are immobilized into the gels firstly and the gels are broken into smaller particles when the immobilization system is injected into reservoir. Underground water containing calcium begins to permeate into the gels, then the microorganisms grow to hydrolyze urea and secrete EPS. The reaction of precipitation happens immediately as soon as the carbonate anions are generated. Even though we did not measure the EPS in the system, the glue-like adhesive behavior of EPS has been confirmed by previous researches. ${ }^{47,48}$ Meanwhile, EPS could also act as the nucleus of precipitation and promote the proceeding of precipitation..$^{49}$ Therefore, the EPS act as not only the adhesive agent but also the nucleus of precipitation. As more and more precipitations are produced, calcium carbonates aggregate to bigger lump and extend from inside to outside of the gels. When calcium carbonates wrap the gels completely, the gel pieces will contact and aggregate under the hydraulic force. The calcium carbonate and EPS mixture attached on the gels continue growing until the gel pieces are connected. As a consequence, the gels achieve the effect of microbial selfhealing.

Self-healing technique has been reported for long time. However, to our knowledge, it is the first report about the selfhealing technology via microorganisms. Wang et al. used silica gel or polyurethane to immobilize bacteria for self-healing concrete ${ }^{50}$ What different with our study is that the silica gel or polyurethane as the carrier is used to protect the bacteria due to the high $\mathrm{pH}(>12)$ environment inside concrete, while the microbially induced calcium carbonate precipitation is the plugging body. However, our study depends on the synergistic effect of calcium carbonate biomineral and EPS to achieve the self-healing of gels. Calcium carbonate biomineral and EPS act as the adhesive agent, and calcium carbonate simultaneously acts also as the plugging agent. Therefore, microbially selfhealing gel and calcium carbonate are the plugging body. In striking contrast to conventional cross-linked or thermoreversible macromolecules, these systems, when broken or cut, can be simply repaired by bringing together fractured surfaces to self-healing at room temperature, ${ }^{51}$ microbial self-healing technique mainly depends on the metabolic activity of microorganisms that produce or secrete some metabolites, such as EPS, bioacid, biogas and biosurfactant, to realize healing. Tuncaboylu et al. reported tough and self-healing hydrogels formed via hydrophobic interactions. ${ }^{27}$ As we know, hydrophobic interaction is extremely weak that can be affected easily by surrounding environment while the microbial self-healing gels in our study principally rely on the synergistic effect of calcium carbonate biomineral and EPS. Calcium carbonate biomineral as an abiotic precipitation is quite stable in the environment. Therefore, it does not affect the plugging effect even when the microbes die due to running out of the nutrients. Furthermore, the concentrated medium is immobilized into the gels to feed microorganisms and realize the self-healing ability. By changing the pattern of injected nutrients from bulk feeding.

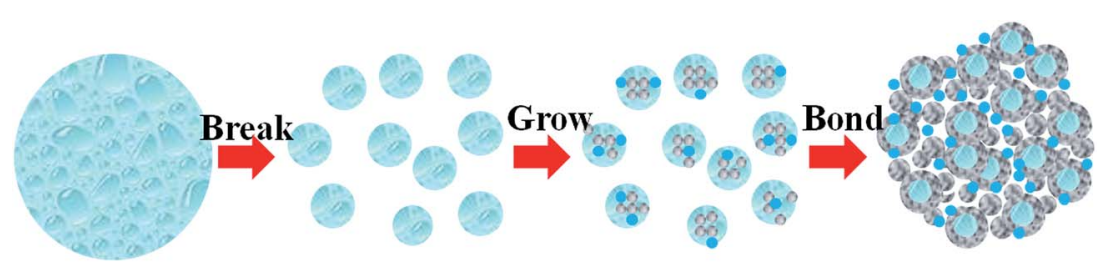

Fig. 9 The mechanism of microbial self-healing gel namely bridge effect among gel, EPS and calcium carbonate. $\bullet \mathrm{Gel}_{\bullet} \mathrm{EPS} \bullet \mathrm{CaCO}_{3}$. 
in conventional microbial enhanced oil recovery ${ }^{52}$ to precise point feeding in this study, it can reduce not only the cost but also the contamination to the underground environment. Meanwhile, due to slow mass transformation in the gel, the selfhealing action will not happen as soon as the microbial immobilization gel is injected into the underground. This will avoid the risk that the self-healing gel reacts too fast to plug the injection well during the transport to the reservoir, especially in the polymer flooding. ${ }^{53}$ It is worth mentioning that our immobilization gel can also protect the microorganisms being shocked from the underground environment and provide a suitable habitat for the microorganisms to adapt to the new environment.

In summary, due to unique self-healing property, strong link, the simplicity and the low cost of raw ingredients (urea), microbial self-healing gel opens a new direction about selfhealing for EOR.

\section{Conclusions}

In this study, microbial self-healing gels that principally rely on the synergistic effect of calcium carbonates biomineral and EPS were designed. Some conclusions are shown as bellow: (1) the optimum immobilization formula less affected the microorganisms activity that was $55.91 \%$ of microorganisms suspension. (2) The microscope images showed the uniform distribution of the microorganisms in the gels and the porosity of gels was propitious to the immobilization of the microorganisms and mass transfer. (3) Oil recovery was improved from $45.37 \%$ to $88.32 \%$ in sand-packed columns experiments. (4) Microbial self-healing gel was achieved via synergistic bridge effect among gel, EPS and biomineral and the strength analysis revealed the excellent performance. (5) This microbial selfhealing gel shows a promising application prospect to enhanced oil recovery.

\section{Acknowledgements}

The authors would like to acknowledge the financial support of Petro China Innovation Foundation (2014D-5006-0205), the Collaborative Innovation Center of Suzhou Nano Science and Technology, the Program for Changjiang Scholars and Innovative Research Team in University, and the Fundamental Research Funds for the Central Universities.

\section{References}

1 J. P. Dorian, H. T. Franssen and D. R. Simbeck, Energy Policy, 2006, 34, 1984-1991.

2 M. A. Sohal, G. Thyne and E. G. Søgaard, Energy Fuels, 2016, 30, 1904-1914.

3 C. Hall, P. Tharakan, J. Hallock, C. Cleveland and M. Jefferson, Nature, 2003, 426, 318-322.

4 I. S. a. R. Sandrea, Oil Gas J., 2007, 105, 1-8.

5 L. R. Brown, Curr. Opin. Microbiol., 2010, 13, 316-320.

6 R. T. Bachmann, A. C. Johnson and R. G. J. Edyvean, Int. Biodeterior. Biodegrad., 2014, 86, 225-237.
7 N. Youssef, M. S. Elshahed and M. J. McInerney, Adv. Appl. Microbiol., 2009, 66, 141-251.

8 R. Sen, Prog. Energy Combust. Sci., 2008, 34, 714-724.

9 A. Z. Abidin, T. Puspasari and W. A. Nugroho, Procedia Chem., 2012, 4, 11-16.

10 N. J. Lai, X. P. Qin, Z. B. Ye, C. X. Li, K. Chen and Y. Zhang, J. Pet. Sci. Eng., 2013, 112, 198-205.

11 N. J. Lai, Y. Zhang, Q. Xu, N. Zhou, H. J. Wang and Z. B. Ye, RSC Adv., 2016, 6, 32586-32597.

12 A. Shah, R. Fishwick, J. Wood, G. Leeke, S. Rigby and M. Greaves, Energy Environ. Sci., 2010, 3, 700-714.

13 C. J. Zou, M. Wang, Y. Xing, G. H. Lan, T. T. Ge, X. L. Yan and T. Gu, Biochem. Eng. J., 2014, 90, 49-58.

14 E. J. Gudina, J. F. B. Pereira, L. R. Rodrigues, J. A. P. Coutinho and J. A. Teixeira, Int. Biodeterior. Biodegrad., 2012, 68, 56-64.

15 C. C. Ezeuko, A. Sen, A. Grigoryan and I. D. Gates, Biotechnol. Bioeng., 2011, 108, 2413-2423.

16 V. K. Surasani, L. Li, J. B. Ajo-Franklin, C. Hubbard, S. S. Hubbard and Y. X. Wu, Energy Fuels, 2013, 27, 6538-6551.

17 M. Thullner, Ecol. Eng., 2010, 36, 176-196.

18 T. L. Stewart and H. S. Fogler, Biotechnol. Bioeng., 2001, 72, 353-363.

19 H. Zhu, H. K. Carlson and J. D. Coates, Environ. Sci. Technol., 2013, 47, 8970-8977.

20 A. J. Phillips, E. Lauchnor, J. J. Eldring, R. Esposito, A. C. Mitchell, R. Gerlach, A. B. Cunningham and L. H. Spangler, Environ. Sci. Technol., 2013, 47, 142-149.

21 M. O. Cuthbert, L. A. McMillan, S. Handley-Sidhu, M. S. Riley, D. J. Tobler and V. R. Phoenix, Environ. Sci. Technol., 2013, 47, 13637-13643.

22 A. J. Phillips, A. B. Cunningham, R. Gerlach, R. Hiebert, C. C. Hwang, B. P. Lomans, J. Westrich, C. Mantilla, J. Kirksey, R. Esposito and L. Spangler, Environ. Sci. Technol., 2016, 50, 4111-4117.

23 A. Yasin, H. Z. Li, Z. Lu, S. U. Rehman, M. Siddiq and H. Y. Yang, Soft Matter, 2014, 10, 972-977.

24 D. C. Tuncaboylu, M. Sahin, A. Argun, W. Oppermann and O. Okay, Macromolecules, 2012, 45, 1991-2000.

25 A. Bin Ihsan, T. L. Sun, T. Kurokawa, S. N. Karobi, T. Nakajima, T. Nonoyama, C. K. Roy, F. Luo and J. P. Gong, Macromolecules, 2016, 49, 4245-4252.

26 Z. Gong, G. Zhang, X. Zeng, J. Li, G. Li, W. Huang, R. Sun and C. Wong, ACS Appl. Mater. Interfaces, 2016, 8, 24030-24037.

27 D. C. Tuncaboylu, M. Sari, W. Oppermann and O. Okay, Macromolecules, 2011, 44, 4997-5005.

28 Q. F. Wang, S. M. Li, Z. Y. Wang, H. Z. Liu and C. J. Li, J. Appl. Polym. Sci., 2009, 111, 1417-1425.

29 X. Hao, H. Liu, Z. Lu, Y. Xie and H. Yang, J. Mater. Chem. A, 2013, 1, 6920.

30 V. Mishra, S. H. Jung, H. M. Jeong and H. I. Lee, Polym. Chem., 2014, 5, 2411-2416.

31 X. Hao, W. Zhou, R. Yao, Y. Xie, S. u. Rehman and H. Yang, J. Mater. Chem. A, 2013, 1, 14612.

32 Y. Zhao, J. Zhou, X. Xu, W. Liu, J. Zhang, M. Fan and J. Wang, Colloid Polym. Sci., 2008, 287, 237-241.

33 L. Fu, Z. W. Ding, J. Ding, F. Zhang and R. J. Zeng, Appl. Microbiol. Biotechnol., 2015, 99, 7925-7936. 
34 M. Friedman and C. E. Levin, J. Agric. Food Chem., 2008, 56, 6113-6140.

35 C. Bailliez, C. Largeau and E. Casadevall, Appl. Microbiol. Biotechnol., 1985, 23, 99-105.

36 X. Tian, Q. Liao, W. Liu, Y. Z. Wang, X. Zhu, J. Li and H. Wang, Int. J. Hydrogen Energy, 2009, 34, 4708-4717.

37 M. Nemati, E. A. Greene and G. Voordouw, Process Biochem., 2005, 40, 925-933.

38 J. L. White, J. E. Goddard and H. M. Phillips, J. Pet. Technol., 1973, 25, 143-150.

39 S. Wei, H. Cui, Z. Jiang, H. Liu, H. He and N. Fang, Braz. J. Microbiol., 2015, 46, 455-464.

40 H. Rong, C. X. Qian and L. Z. Li, Constr Build Mater, 2012, 36, 687-694.

41 T. Wang, B. X. Leng, R. C. Che and Z. Z. Shao, Langmuir, 2010, 26, 13385-13392.

42 M. Wagner, Dev. Pet. Sci., 1991, 31, 387-398.

43 X. Hao, H. Liu, Y. J. Xie, C. Fang and H. Y. Yang, Colloid Polym. Sci., 2013, 291, 1749-1758.
44 L. Stevens, P. Calvert, G. G. Wallace and M. I. H. Panhuis, Soft Matter, 2013, 9, 3009-3012.

45 V. S. Whiffin, PhD thesis, Murdoch University, 2004.

46 L. Cheng, M. A. Shahin and R. Cord-Ruwisch, Geotechnique, 2014, 64, 1010-1013.

47 N. Her, G. Amy, A. Plottu-Pecheux and Y. Yoon, Water Res., 2007, 41, 3936-3947.

48 P. V. Bhaskar, H. P. Grossart, N. B. Bhosle and M. Simon, FEMS Microbiol. Ecol., 2005, 53, 255-264.

49 F. X. Kang, P. B. Hamilton, J. Long and Q. Wang, Fundam. Appl. Limnol., 2010, 176, 173-181.

50 J. Y. Wang, K. Van Tittelboom, N. De Belie and W. Verstraete, Constr Build Mater, 2012, 26, 532-540.

51 D. Y. Wu, S. Meure and D. Solomon, Prog. Polym. Sci., 2008, 33, 479-522.

52 Z. Song, W. Zhu, G. Sun and K. Blanckaert, Appl. Microbiol. Biotechnol., 2015, 99, 6551-6561.

53 W. Wang, Y. Liu and Y. Gu, Colloid Polym. Sci., 2003, 281, 1046-1054. 